\title{
STRUCTURE OF RECONFIGURABLE MANUFACTURING SYSTEMS
}

\author{
Mulc, T.; UdilJAK, T. \& CiglaR, D.
}

Abstract: The structure and production of special machine tools is under strong pressure by the automotive industry as the main users of these machines. This industry dictates the conditions and standards of product quality, demanding the implementation of modern technology, higher levels of automation, flexibility and efficiency, and at the same time put a strong pressure on price reduction. The classical construction of special machines has become questionable because the modular concept and reconfiguration becomes a promising approach towards future manufacturing machines, in which manufacturing is independent of changes. Reconfigurable machines form a new class of machines and this article outlines the fundamental properties of modernly designed flexible manufacturing cells, and provides an overview of the achievements and development of special manufacturing machines in the company SAS-Strojogradnja, Croatia.

Key words: Reconfigurable manufacturing systems (RMS), Reconfigurable machine tool (RMT), Flexible manufacturing systems (FMS), modular concept, special manufacturing machines
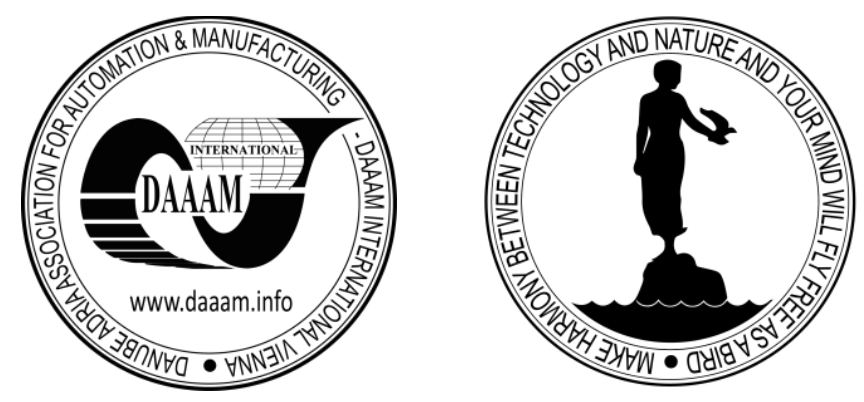

Authors' data: Dr. Sc. Mulc, T[ihomir]*, Univ.Prof. Dipl.-Ing. Dr. Udiljak, T[oma]*; Univ.Prof. Dipl.-Ing. Dr. Ciglar, D[amir]**, *SAS-Strojogradnja, Domovinskog rata 1, 23000 Zadar, Croatia; **University of Zagreb, Faculty of Mechanical Engineering and Naval Architecture, Ivana Luciča 5, 10005, Zagreb, tihomir@ sas-strojogradnja.hr, toma.udiljak@fsb.hr,damir.ciglar@fsb.hr

This Publication has to be referred as: Mulc, T[ihomir]; Udiljak, T[oma] \& Ciglar, D[amir] (2015). Structure of Reconfigurable Manufacturing Systems, Chapter 32 in DAAAM International Scientific Book 2015, pp.369-390, B. Katalinic (Ed.), Published by DAAAM International, ISBN 978-3-902734-05-1, ISSN 1726-9687, Vienna, Austria

DOI: $10.2507 /$ daaam.scibook.2015.32 
Mulc, T.; Udiljak, T. \& Ciglar, D.: Structure of Reconfigurable Manufacturing Syst...

\section{Introduction}

Unpredictable market changes caused by global competition, customer demands and increasingly rapid changes in technology have created new relationships, technologies and societies. Modern market demands and high investment uncertainty have led to an increase in the number of product variations, and a reduction in the time for product development and its lifespan. Manufacturers are required to develop global strategies in order to determine where they stand in the development of manufacturing and their production, how to integrate into the global supply chain and how to improve their own productivity. In order to become more competitive globally, it is necessary to closely monitor trends on the global market, such as:

- shorter product service life,

- greater number of product versions,

- fewer orders, thus reducing the size of individual production series,

- customer needs and wants have greater influence in shaping products,

- frequent changes of customer needs due to market competition,

- rapid production changes and cheaper products of higher quality,

- increased share of small series and custom order production,

- strong international competition.

The key to global success is a rapid response to customer needs and market changes, through new manufacturing concepts based on the development of innovative products. There is a strong need to improve product quality and to ensure their high adaptability to customer needs. In industrialised countries, the market creates an environment of cost-acceptable, personalised products. With this, each product is different and made to suit the needs of an individual customer (individual market). Product design and functionality need to be aligned with the cultural, regional, climatic and purchasing power factors of those customers of the target market. The development platform should be modular, and expanded in a step-wise fashion. One of the ways to respond to market demands is to possess reconfigurable production systems with capacities that are easy to change and adjust, and whose functionality can be altered for a new product type at minimal cost in a short period of time. There must be clear economic justification for the use of such systems.

The economic viewpoint relates to the possibility of rationalising production:

- shorter machining times,

- reduction of occupation of machine tool,

- shorter times of the workpiece in the workshop,

- reduction of workshop size,

- reduction of staff manning the machine in the workshop,

- shorter manufacturing times,

- reduction of capital investments in relation to the appropriate conventional solutions,

- increase of efficiency of manufacturing facilities. 
Based on the above, it can be established that the market demands increasing productivity, high quality and flexibility, at a low price. These fundamentally contrary requirements of manufacturing machines and systems are difficult to achieve simultaneously. It is necessary to achieve an optimum level between productivity, flexibility, quality and price. These global trends can only be met by manufacturing systems that enable:

- high productivity,

- an acceptable price during the product life cycle,

- production of high quality products,

- rapid response to changing market conditions,

○ increasing additional capacities as the market grows,

$\checkmark$ changing functionality as the product changes.

Some of the solutions directed at increasing efficiency are found in new technologies and new production system concepts. Table 1 gives a brief overview of the influences of individual technologies for system efficiency.

\begin{tabular}{|c|c|c|c|c|c|}
\hline \multirow[b]{2}{*}{$\begin{array}{l}\text { TECHNOLOGY } \\
\text { INNOVATIONS }\end{array}$} & \multirow[b]{2}{*}{ NEW TECHNOLOGIES } & \multicolumn{4}{|c|}{ DEMANDS } \\
\hline & & $\stackrel{0}{0}$ & 忌 & 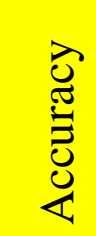 & 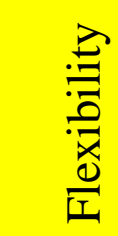 \\
\hline \multirow{6}{*}{$\begin{array}{l}\text { MACHINING } \\
\text { TECHNOLOGIES }\end{array}$} & High Productive Machining & $\mathrm{Y}$ & $\mathrm{X}$ & $\mathrm{Z}$ & $\mathrm{Z}$ \\
\hline & High Speed Machining & $\mathrm{Y}$ & $\mathrm{Z}$ & $\mathrm{X}$ & $\mathrm{Z}$ \\
\hline & Dry Machining & $\mathrm{X}$ & $\mathrm{Z}$ & $\mathrm{Z}$ & $\mathrm{Z}$ \\
\hline & Hard Machining & $\mathrm{X}$ & $\mathrm{Z}$ & $\mathrm{Y}$ & $\mathrm{Z}$ \\
\hline & Laser Machining & $\mathrm{Y}$ & $\mathrm{X}$ & $\mathrm{X}$ & $\mathrm{Z}$ \\
\hline & Micro Machining & $\mathrm{Z}$ & $\mathrm{Z}$ & $\mathrm{X}$ & $\mathrm{Z}$ \\
\hline \multirow{3}{*}{ MACHINING SYSTEMS } & Reconfigurable Machine Tools & $\mathrm{Y}$ & $\mathrm{Y}$ & $\mathrm{Y}$ & $\mathrm{X}$ \\
\hline & Complete Machining & $\mathrm{X}$ & $\mathrm{X}$ & $\mathrm{X}$ & $\mathrm{Z}$ \\
\hline & Flexible Machining Lines & $\mathrm{X}$ & $\mathrm{Z}$ & $\mathrm{Y}$ & $\mathrm{X}$ \\
\hline X - Primary impact & Y - Secondary impact & \multicolumn{4}{|c|}{ Z - Minimal impact } \\
\hline
\end{tabular}

Tab. 1. New technologies and new concepts of manufacturing machines

A new technology certainly worth mentioning is High Speed Machining (HSM). With this, cutting speed is increased, and the mechanisms of particle generation and removal are altered. Increasing processing speed with reduced feed and depth lead to a reduced cutting force, which is suitable in machining thin-walled objects. At high cutting speeds, the majority of heat is transferred in the separated particles, while the machining object and tool remain relatively cool. In recent years, there has been a clear trend to develop high-speed machining technologies directed at machining difficult and hardened materials, particularly in the manufacture of medical devices. An important 
Mulc, T.; Udiljak, T. \& Ciglar, D.: Structure of Reconfigurable Manufacturing Syst...

condition for the application of high-speed machining in hardened materials is the use of an appropriate cutting material/coating, the careful selection of machining parameters, and an appropriate machining strategy. The strong influence of developing information technologies, management systems, sensors, drive systems and advances in tools should also be noted as generators of innovation in the field of production technologies.

The optimal capacities of new technologies can only be fully used if the construction of the machine tool enables increased kinematic and dynamic demands, and if they use contemporary tools. These demands have emerged with the appearance of new concepts of building machine tools. The production concept, developed for the purpose of resolving a machining issue, depends on product shape, product size and required machining operations. Figure 1 shows the area of application of different production systems in the function of flexibility, level of automation, number of different workpieces, and annual production.

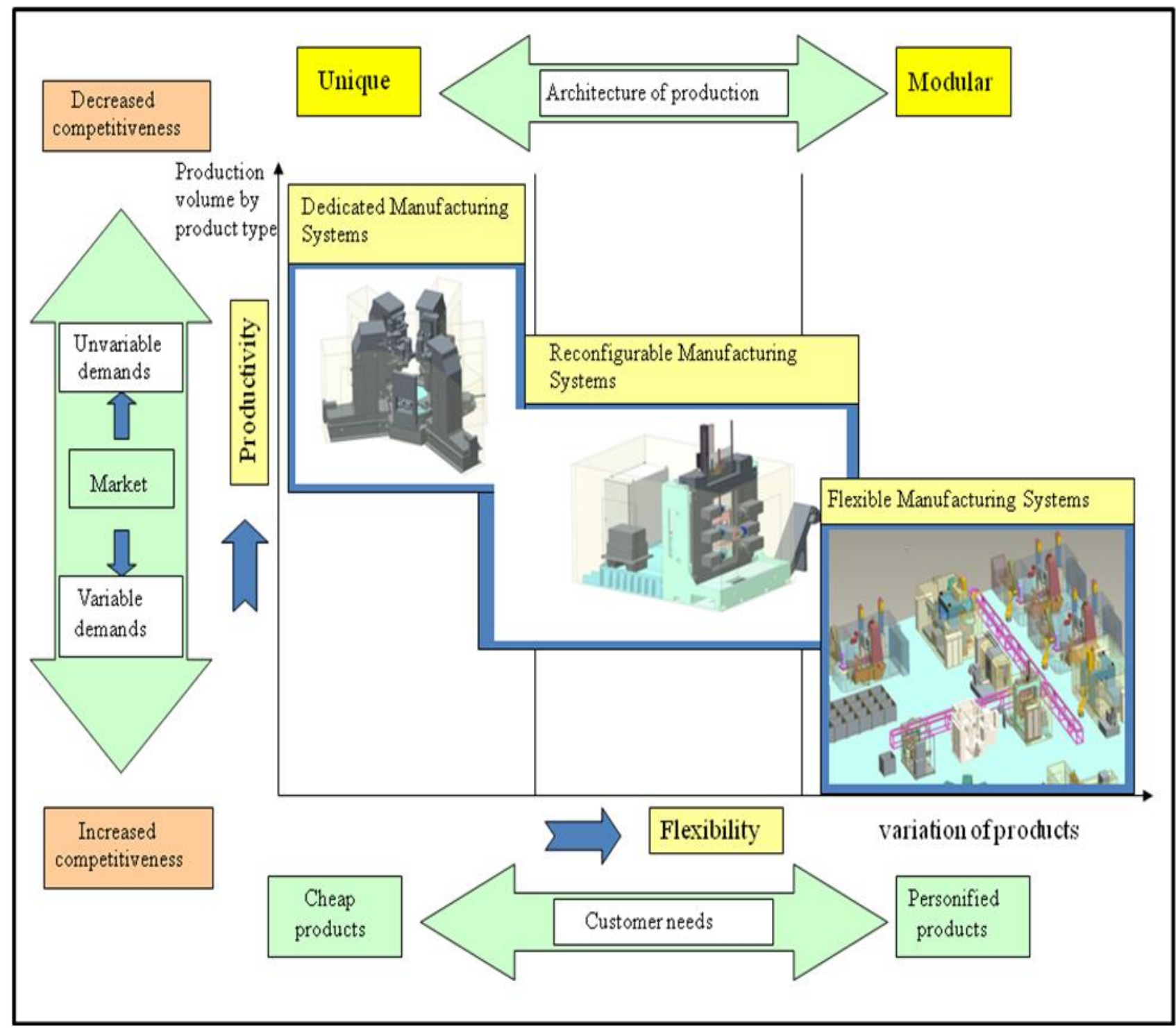

Fig. 1. Area of activity of different manufacturing systems in the function of flexibility, level of automation, variety and number of different workpieces 
The two main traditional methods used in the industrial production of medium and large series are Dedicated Manufacturing Systems (DMS) and Flexible Manufacturing System (FMS), (Koren, 2010). DMS is used when a series of products is large and constant, and when the product does not change. FMS is used when it is necessary to product a relatively small quantity of product, with many envisaged modifications, or for the simultaneous production of different product types on the same line. Special machine tools, as an integral part of DMS, are strictly intended for the mass production of a limited scope of product variations, while the machining centers that are an integral part of the FMS are limited to smaller series with greater product diversity. The FMS concept can meet changing market demands, though it has lower productivity, higher associated costs, and is more complex in comparison to the DMS system (Mehrabi et al., 2002).

A compromise solution aiming to meet the demands for productivity and flexibility was achieved with the appearance of Reconfigurable machine tools (RMT), in which the machine structure is quickly adapted to the production capacity needs and functionalities with the product family. A previously conceived series of necessary activities envisaged in the description of the product family is executed with high reliability, repeatability and productivity. The limited flexibility allows for a lower investment costs on the one hand, and a rapid response for subsequent product changes on the other. Machines are configured from basic modules (both hardware and software). The rapid integration of new technologies is supported to improve efficiency and adaptation to customer needs, while retaining high productivity levels. This enables the addition, removal or modification of the functional capacities. The machine structure is adapted to production capacities dictated by the market or through the installation of new technologies. This ensures flexibility for a specific family of products, with a significant increase in the level of efficiency and productivity.

Figure 1 shows that each production philosophy secures its area of activity, which is then constantly expanded through developments in techniques and technology. Market demands for rapid changes to production capacities in terms of product type and quantity, high quality and lower cost implies a modular and adaptable production structure. Therefore, a modular concept to building flexible machining cells, with an integration of an automated system and application of HSM technology provide a solution and response to market demands.

\section{Analysis of various production system models}

Production capacity and competitiveness of machining systems is seen through increasing productivity, flexibility and quality of products. For this reason, it is necessary to assure continuous dynamic introduction of radical novelties into production. The application of modern management and drive systems, increasing degrees of automation and autonomy of machining cells, and introductions of technology in High Speed Machining (HSM) have significantly altered production 
Mulc, T.; Udiljak, T. \& Ciglar, D.: Structure of Reconfigurable Manufacturing Syst...

conditions. This has opened the possibility of development of new machining concepts with substantially higher efficiency and flexibility. The main and auxiliary machining times have been reduced, system autonomy has been increased, and the thinking behind the cutting process, tool shaping and the machine tool has changed. Changes in performance for contemporary flexible manufacturing cells have enabled their penetration into certain segments of producing medium and large series, which until recently were dominated by classical linear and circular manufacturing systems (Jüng,1997). More significant production variations have led to the increasing ability to adapt products to suit customer needs, in the form of Mass Customization (MC). Responses to these new manufacturing conditions have been provided in the innovative technologies integrated in Reconfigurable Manufacturing Systems (RMS). Table 2 (Mehrabi et al., 2000) shows the main comparisons between the different production systems.

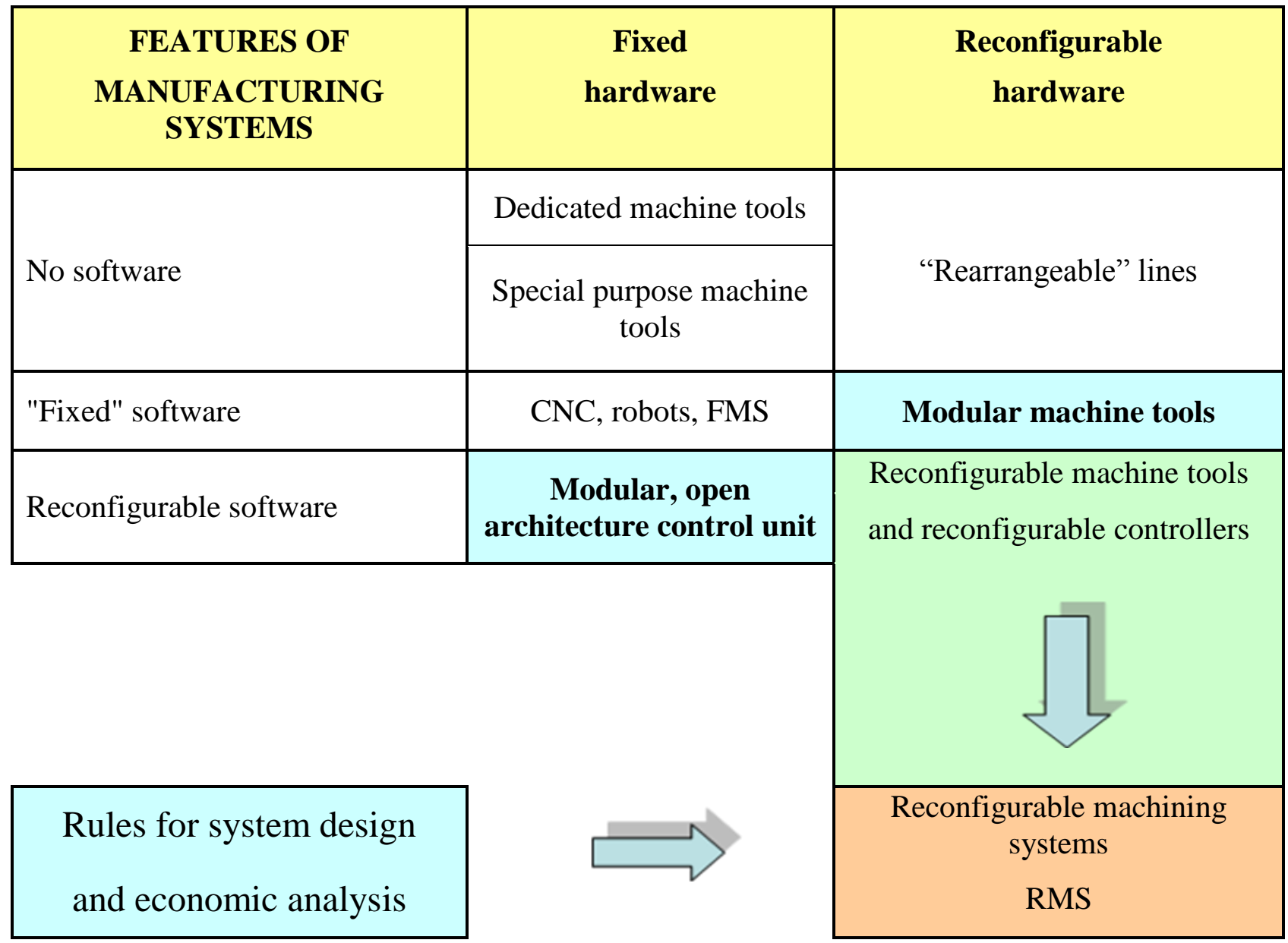

Tab. 2. Comparison of hardware properties of manufacturing systems

The table 2 shows that production systems based on a modular construction are more complex and flexible. Modularity requires planning the mechanical and electrical interfaces. In addition to hardware reconfigurability, it is also necessary to emphasize software reconfigurability, as the basis for creating new quality. Therefore, adaptation to current market demands, while retaining high productivity levels, is the fundamental 
guideline for the further development of manufacturing systems. Table 3 provides an overview of the main characteristics of individual manufacturing system concepts.

Table 3 shows that all the concepts have their primarily area of activity. However, these are constantly being expanded through the use of innovation technology, with a certain degree of overlap in the border areas.

\begin{tabular}{|c|c|c|c|}
\hline \multirow{2}{*}{ SYSTEM FEATURES } & \multicolumn{3}{|c|}{ MODELS OF MANUFACTURING SYSTEMS } \\
\hline & $\begin{array}{c}\text { Dedicated } \\
\text { systems }\end{array}$ & Flexible systems & $\begin{array}{l}\text { Reconfigurable } \\
\text { systems }\end{array}$ \\
\hline \multicolumn{4}{|l|}{$\begin{array}{l}\text { Production } \\
\text { program }\end{array}$} \\
\hline product range & variety, limited & & \\
\hline $\begin{array}{l}\text { batch sizes } \\
\text { (quantity) }\end{array}$ & large - medium & small - medium & $\begin{array}{c}\text { large - medium - } \\
\text { small }\end{array}$ \\
\hline dynamic & $\begin{array}{c}\text { high - } \\
\text { continuous }\end{array}$ & $\begin{array}{c}\text { small - } \\
\text { continuous/discontinuous }\end{array}$ & $\begin{array}{l}\text { large - medium - } \\
\text { small - continuous }\end{array}$ \\
\hline \multicolumn{4}{|l|}{$\begin{array}{l}\text { Production } \\
\text { equipment }\end{array}$} \\
\hline typ & $\begin{array}{l}\text { specialized, } \\
\text { special }\end{array}$ & universal, specialized & $\begin{array}{l}\text { reconfigurable, } \\
\text { specialized }\end{array}$ \\
\hline flexibility & limited & high & adaptable \\
\hline productivity & high & limited & medium, adaptable \\
\hline Layout & homogenous & inhomogeneous & $\begin{array}{c}\text { changeable and } \\
\text { adaptable }\end{array}$ \\
\hline $\begin{array}{l}\text { Number of } \\
\text { operations at } \\
\text { workplace }\end{array}$ & 1 & $>1$ & $\geq 1$ \\
\hline \multicolumn{4}{|l|}{$\begin{array}{l}\text { System } \\
\text { efficiency }\end{array}$} \\
\hline $\begin{array}{l}\text { technical } \\
\text { efficiency }\end{array}$ & $\geq 0.75$ & $\geq 0.75$ & $\geq 0.85$ \\
\hline $\begin{array}{l}\text { economy } \\
\text { efficiency }\end{array}$ & $\geq 0.80$ & $\geq 0.80$ & $\geq 0.90$ \\
\hline
\end{tabular}

Tab. 3. Characteristics of manufacturing system models (Vukovic et al., 2010) 
Mulc, T.; Udiljak, T. \& Ciglar, D.: Structure of Reconfigurable Manufacturing Syst...

\subsection{Dedicated manufacturing systems based on modular construction}

With the increasing size of product series, particularly in the automotive industry, production lines have emerged that are intended for the performance of specialised tasks, adapted to executing dedicated machining operations. In this area, automation has played an important role. The basic aims of the introduction of production automation are greater productivity, better quality of machining and reduction of production costs. The extent of automation that can be used cost-effectively depends on:

- required annual quantity of products,

- range of products and series size,

- quantity of products to be manufactured over a long period,

- complexity of product shapes

- product size.

Dedicated Manufacturing Systems are designed for the production of large quantities of a smaller number of different products. In their traditional form, these include highly productive, specialised equipment of limited flexibility. Operations and inter-operation transport are automated. Inter-operation transport implies the automatic delivery of a workpiece through the machining time at mutually connected machining stations. It is very difficult to rebuild or re-arrange such a line. This rigid automation has it advantages, though it hinders the development and improvement of products. Product design cannot be changed. In order to change the product or product versions, the production lines must be altered. Building a specialised processing machine depends on the workpiece, technological order of operations, processing requirements, and the quantity of series per year. They are envisaged for one or more work tasks, and have a significant level of automation, with low flexibility. The connections between machining stations is achieved in a linear or circular transport system. Processing units can be dedicated or flexible. Modular construction and a high level of standardisation of individual components are the basis for special machine tools. The standards of building parts can be classified into several different groups:

- Center base (DIN 69513) is the central part of rotary manufacturing machines, around which the processing units are placed,

- Rotary index table (DIN 69514) moves the workpiece to each subsequent work station, and at the end of the process to the emptying station,

- Transfer device/Tact mechanism carries the object from station to station in the line stroke,

- Centerline Unit/Central column for longitudinal processing systems (DIN 69521) enables the installation of side and console units,

- Wing base (DIN 69512) for the receipt of slide units (DIN 69523),

- Vertical column units (DIN 69525) allows for the receipt of slide units and similar installation components, 
- Slide units (DIN 69572) are standardised into eight groups (by width and stroke). For each nominal size of 125 to 630 , there are two available strokes. Strokes range from 160 to $630 \mathrm{~mm}$,

- Working units are spindles with rotating tools. Tool rotation is achieved by an electric motor via transmission on the screw which contains a tool clamp and tool (drilling units - DIN 69641, milling units - DIN 69643, facing units - DIN 69642, expanding, cutting threads, relaxing, etc.). Several types of working units can be distinguished:

○ Single spindle units without a drive system (feeding is achieved by the slide unit), Figure $2 \mathrm{a}$

- Single spindle units with own drive system in direction of the axis (quill), Figure $2 b$

○ Multiple-spindle head for drilling two or more holes and threading - DIN 6902, (fixed drilling image, changeable), Figure 2c.

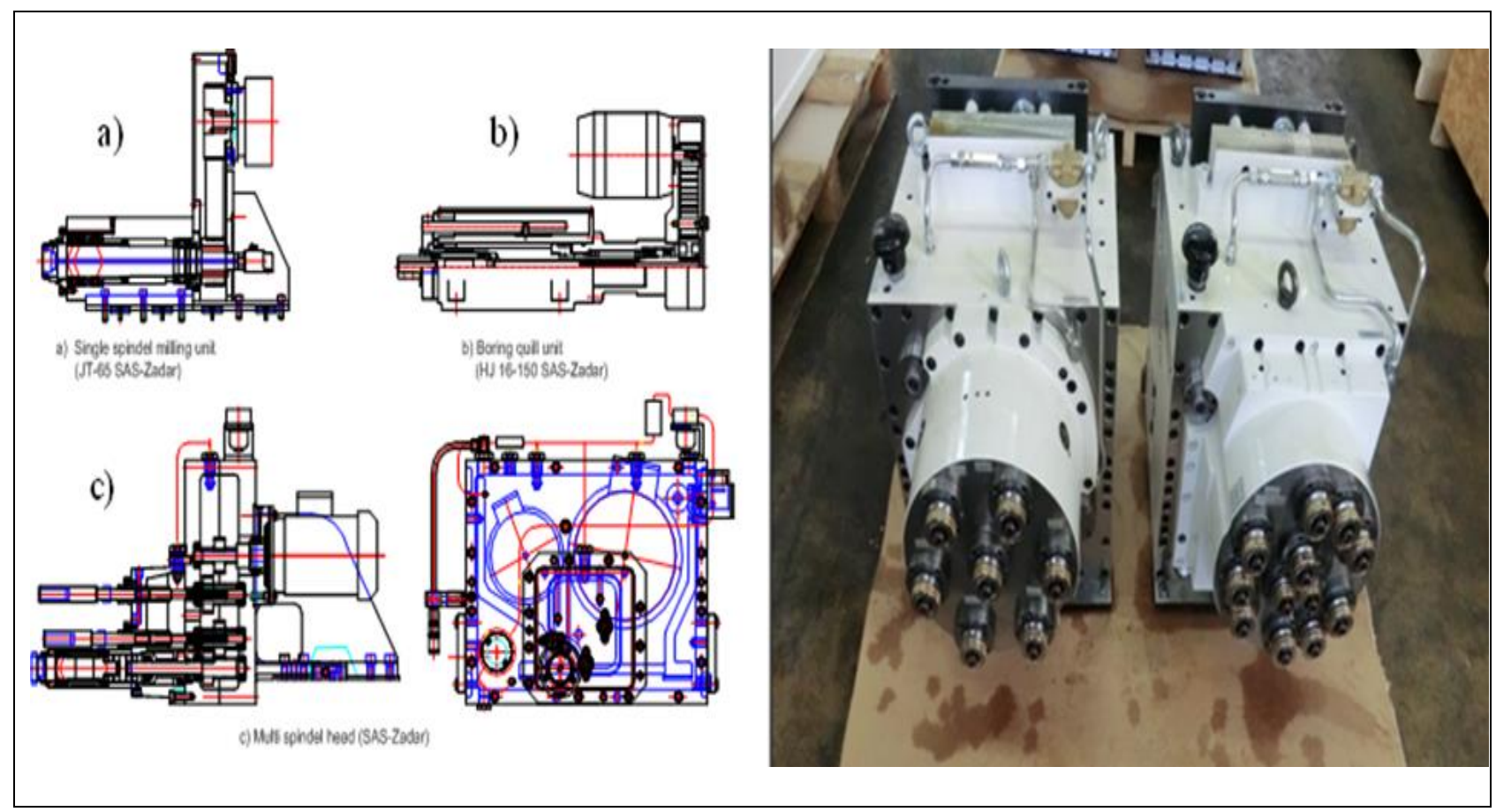

Fig. 2. Standard processing unit (Brochures SAS, 2014)

Therefore, the basis for building special machines is tied to modularity and standardisation, without which it would be virtually impossible to meet short delivery deadlines and demanding machine quality, at low prices. In line with modern technological trends, the development of special machines is tied to the development of new concepts, flexible modules (rapid processing units, rotary tables with satellites, platforms, clamping devices, etc.), and the introduction of new technologies (rapid processing and contemporary tools), Figure 3.

It is necessary to note that within special machines, there is a variety of configurations that differ significantly in their structure and concept. The structure and concept of the machine is tied to the geometric properties of the workpiece, the 
Mulc, T.; Udiljak, T. \& Ciglar, D.: Structure of Reconfigurable Manufacturing Syst... technological requirements and size of the series. The examples that follow give an overview of the different concepts of special machines.

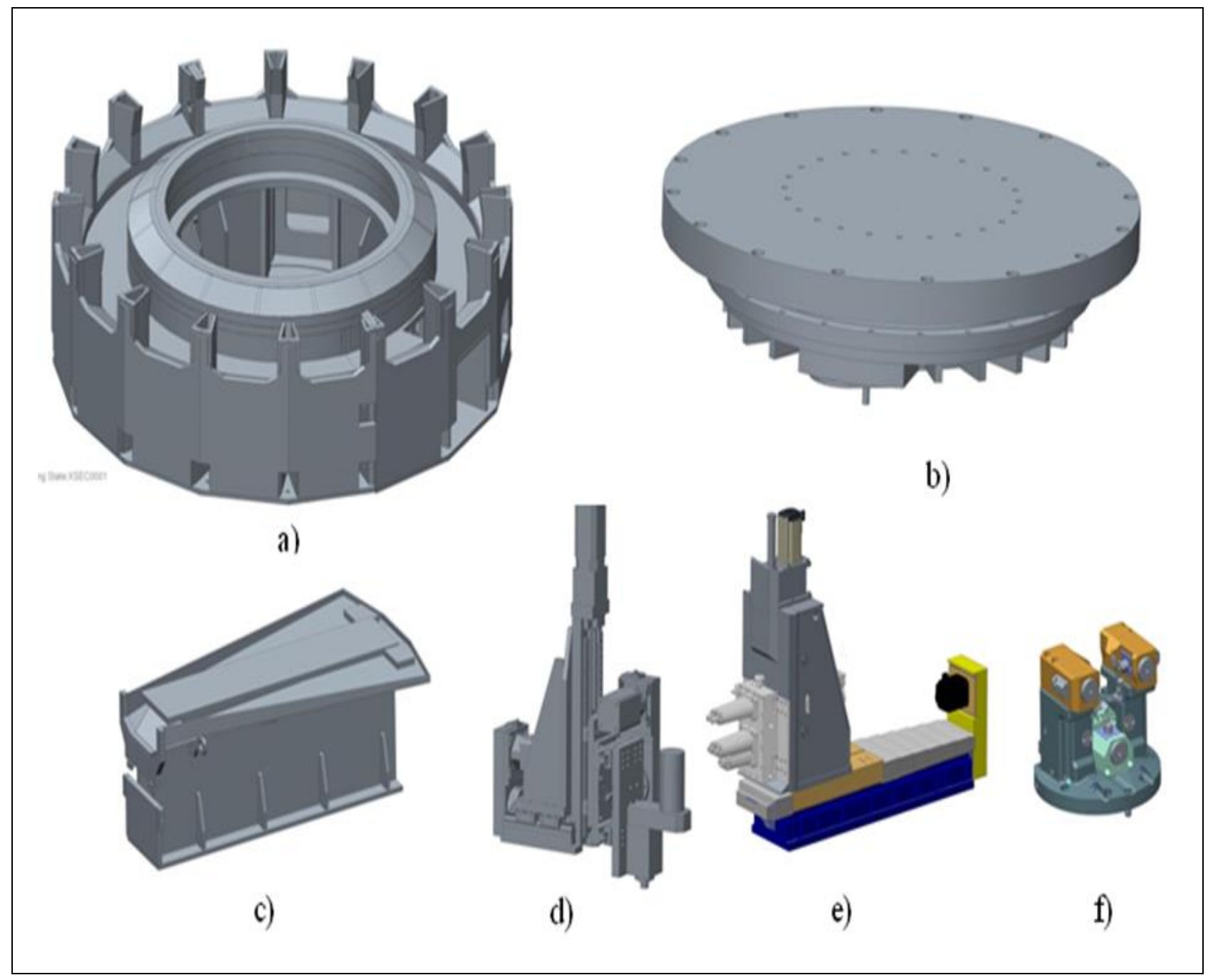

Fig. 3. Construction module of a rotary transfer line: a) central platforms, b) rotary tables, c) side platforms, d) 3-axis units, e) 2-axis units, f) clamping devices

Figure 4 shows the execution of a circular rotary transfer for the processing of disk brakes. The machine stroke is at 18 seconds. Three types of workpieces are processed on the machine. The supply of workpieces is automated at a separate station, during the processing time. The machine is built modularly of standard components: rotary table, linear table, multi-spindle head and clamps. The clamps are on the rotary table, and receive and centre the workpiece. The working stations are positioned around the central column. Another example of a dedicated manufacturing system for the mass procession of various cooler compressor units with similar technological requirements is shown in Figure 5. 


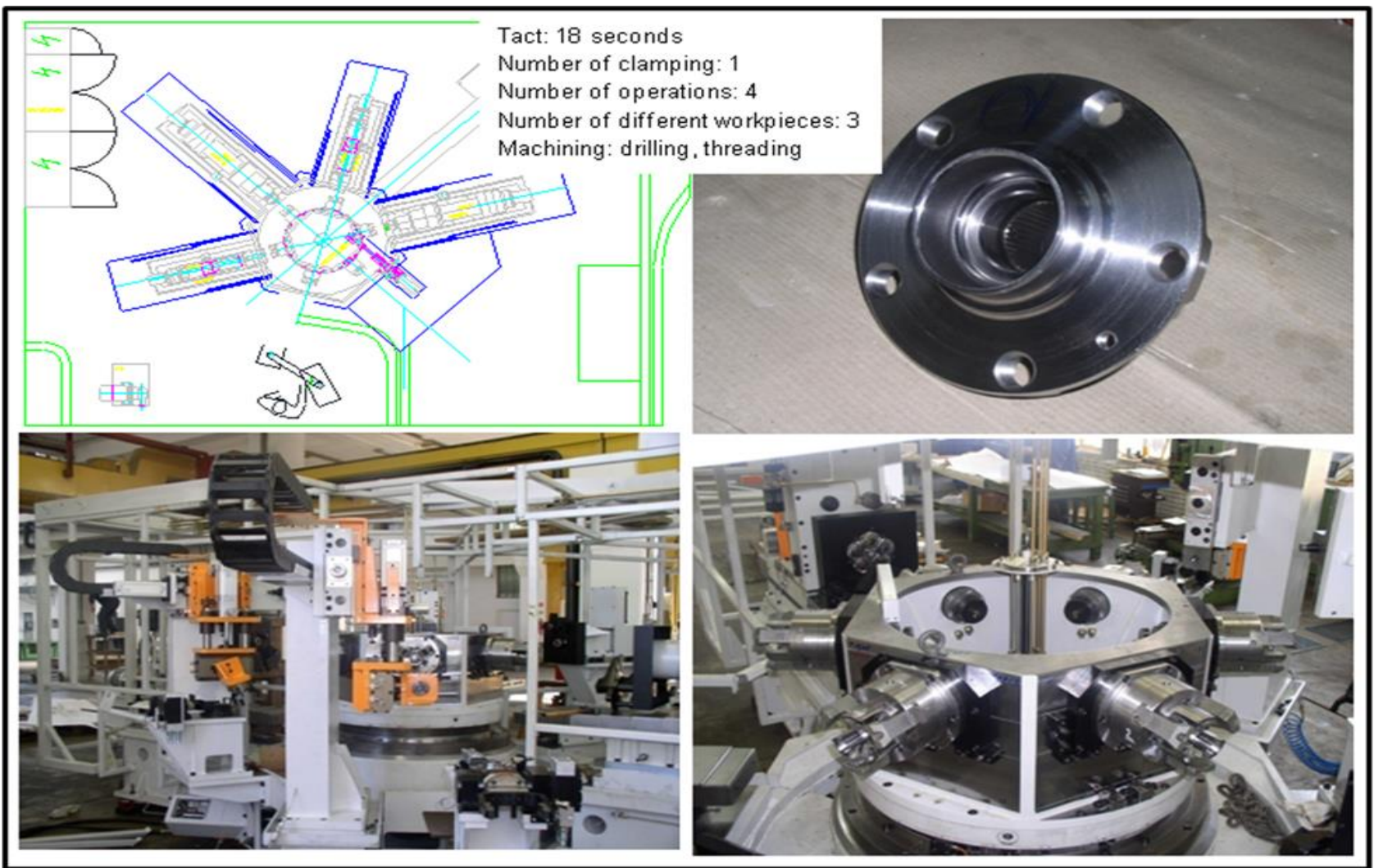

Fig. 4. Special machine with automatic work item alternation (Brochures SAS, 2014)

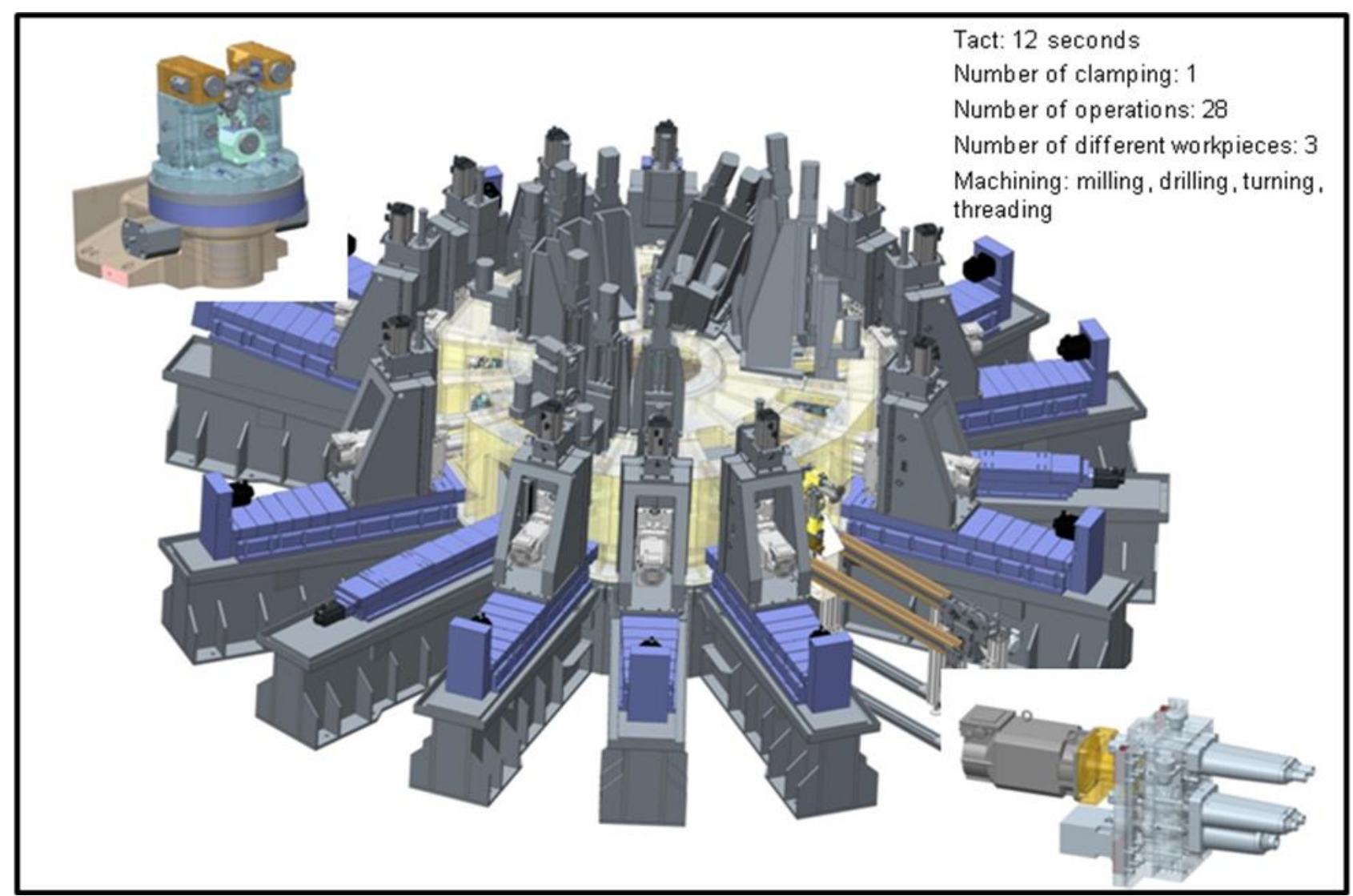

Fig. 5. Circular rotofer for the processing of compressor units (Brochures SAS, 2014)

The processing cells are positioned around the central column, which has has 16 work stations. In the central column, there is a large rotary table (diameter $2.6 \mathrm{~m}$ ) with 
satellites/small rotary tables with clamps. The processing cells are positioned around each work station. Workpiece transfer is automated. The machine simultaneously performs 28 operations: milling, drilling, deep drilling, threading and turning, with a stroke of 12 seconds. Considering the large number of processing cells, high reliability of the components is required, to ensure the machine retains the necessary level of reliability and quality.

The above examples illustrate that special machines have a limited ability to adapt in terms of the possibility of changing the workpiece. The installation units from the standard set of components can be replaced and the clamps adjusted due to the wearing of working units or changes to the technological processes. The modular assembly principle of the special manufacturing machines (standardised building elements) enables rapid assembly, replacement of worn parts or permits limited changes to the workpiece.

\subsubsection{Linking of multiple special machines}

The linking of processing systems via transport and robotisation additionally increases the productivity of manufacturing processes. For complex technological processes that cannot be achieved on a single machine, but requires the use of multiple machines, their linking is justified with the use of palettes and transport systems. An example of an automated processing system for machining the steering knuckle is shown in Figure 6. The machining system is based on two automated machines. Each has several variants of the left and right steering knuckle. During the machine cycle, all operations are carried out through timely tool changes within previously programmed machining parameters. Left and right workpieces are machined simultaneously. Each machine has five stations. The central module is prepared for assembly of the rotary indexing table and five side-modules. On the main rotary indexing table (diameter $2350 \mathrm{~mm}$ ) there are 10 rotary indexing fixtures (diameter 400 mm) supported with Hirth-teeth and NC controlled. Station 1 on the first machine is supported with a portal manipulator with two grippers. The remaining four stations each have an identical 3-NC axis slide unit with magazine and gripper for tool change. The tool magazine contains 10 tools SK 50 - DIN 69871 maximum diameter $250 \mathrm{~mm}$, maximum length $300 \mathrm{~mm}$ and tool change time (chip- to-chip) of 8 seconds. The rotary indexing table includes two hydraulic clamping fixtures for each station. The machine cycle time is 54-64 seconds, depending on the type of workpiece (6 types of workpieces). Machine 2 has three 3-axes units and one fine turning unit. Transport of the workpiece consists of pallets, band and two portal manipulators. During automated work, solid portal manipulators with two grippers enable the accurate transport of workpieces from the transport band to clamping fixtures and back. The measuring station measures the three inner diameters of the bearing seat. On the basis of the measuring results, the tools at station 4 of machine 2 are automatically corrected. The automated work of the machines is controlled through the SIMATIC S5 $115 \mathrm{U}$. Each station is under the control of SINUMERIK 805. Communication between the CNC and CPU is achieved through the net SINEC-L2. This example illustrates that the target function is to achieve optimal flexibility for the appropriate spectrum of products, with the highest degree of automation. Automation and autonomous work demands 
complete control over processes and systems. It is necessary to understand the state of processes and systems, so as to avoid undesirable and unexpected processes and damage to equipment, tools or workpieces. For that purpose, significant efforts are invested in creating reliable and robust sensory methods to supervise processing systems and processes. The use of multi-sensory systems and contemporary processing methods are becoming the standard, as imperative equipment for such systems.

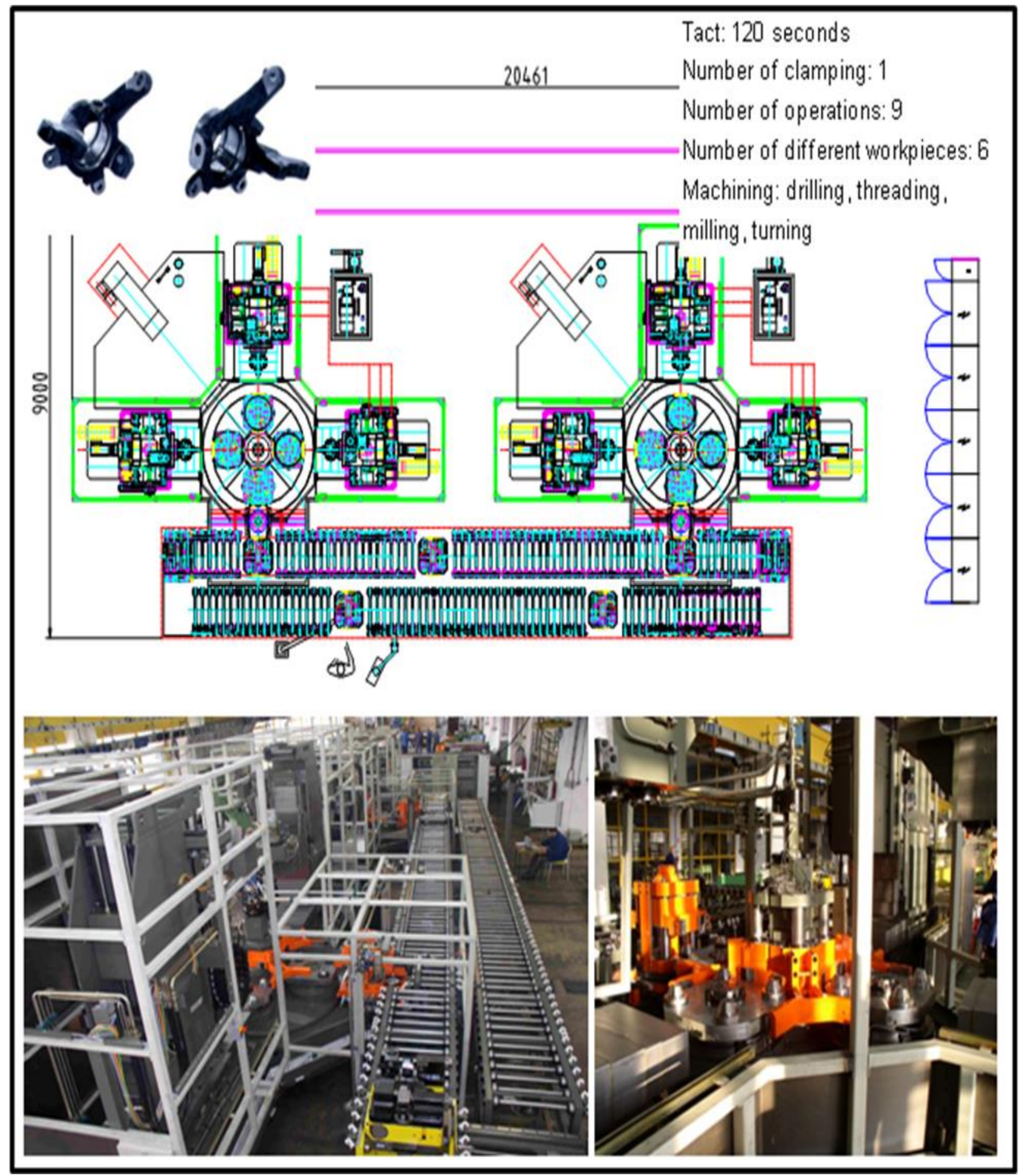

Fig. 6. Flexible system for machining the steering knuckle - MAZ (Brochures SAS, 2014) 
Mulc, T.; Udiljak, T. \& Ciglar, D.: Structure of Reconfigurable Manufacturing Syst...

\subsection{Flexible manufacturing systems}

\subsubsection{Flexible manufacturing cells}

In procuring machines today, it is necessary to factor in the daily changes to market conditions, particularly in the automotive industry. In order to respond to such requirements, it is necessary to ensure high production capacities, high reliability and system availability, with a minimum adjustment period for new products, while reducing equipment prices. Considering the demands of customers, who seek great flexibility, quality and speed, the classical assembly of special machines is becoming increasingly questionable. The development of management systems with the accompanying automation, high feed rate, high-speed spindles and the development of HSM technology have significantly determined machine concepts and management philosophy. An analysis of time spent in processing shows that in classical processing systems, less time is spent on processing, and a larger share is on auxiliary time. This ratio has been significantly altered with a reduction in auxiliary times, the use of fast units with highly dynamic properties, with diverse solutions for the changing of tools and basics of kinematics. Numerous manufacturing machines have been developed with a light construction and small mass, compact structure and high rigidity. In such systems, the motor-spindle of high frequency rotations, cooled by fluids, and with automatic clamping systems (HSK grasps), and feed axes equipped with linear guides, are becoming the standard. Digital control systems, supervision and diagnosis of process states, depending on the degree of automation and flexibility, are becoming increasingly important. The properties of the feed/rate motion (digital motors, ball screws cooled through the centre) are being improved, and linear motors are being gradually introduced for the feed axes. These further raise the level of static and dynamic rigidity, precision, repeatability, thus enabling a simpler construction without transfer mechanisms, reducing noise, and ensuring high reliability and a long lifespan, with minimal maintenance. Reducing series sizes and maximally increasing flexibility have resulted in a replacement of expensive transfer lines with limited flexibility by autonomous fast processing units. Such flexible production cells can only exist as independent cells, or linked through automation. One such general purpose processing cell is the TCF machining center, Figure 7.

Through a gradual expansion of capacity, it is possible to increase the number of processing cells. However, in that case, issues of connections and logistics arise. Such systems become more complex, while also substantially increasing the investment.

For the above reasons, modern processing cells have the advantage of a very small influence on the changes to the workpiece in the phase of machine assembly, high flexibility in relation to the production volume, the possibility of step-wise assembly, an increased technical level of use through parallel processing, or continuation of work with the elimination of an individual work station. The elimination of an individual work station does not result in the halting of the entire system. 


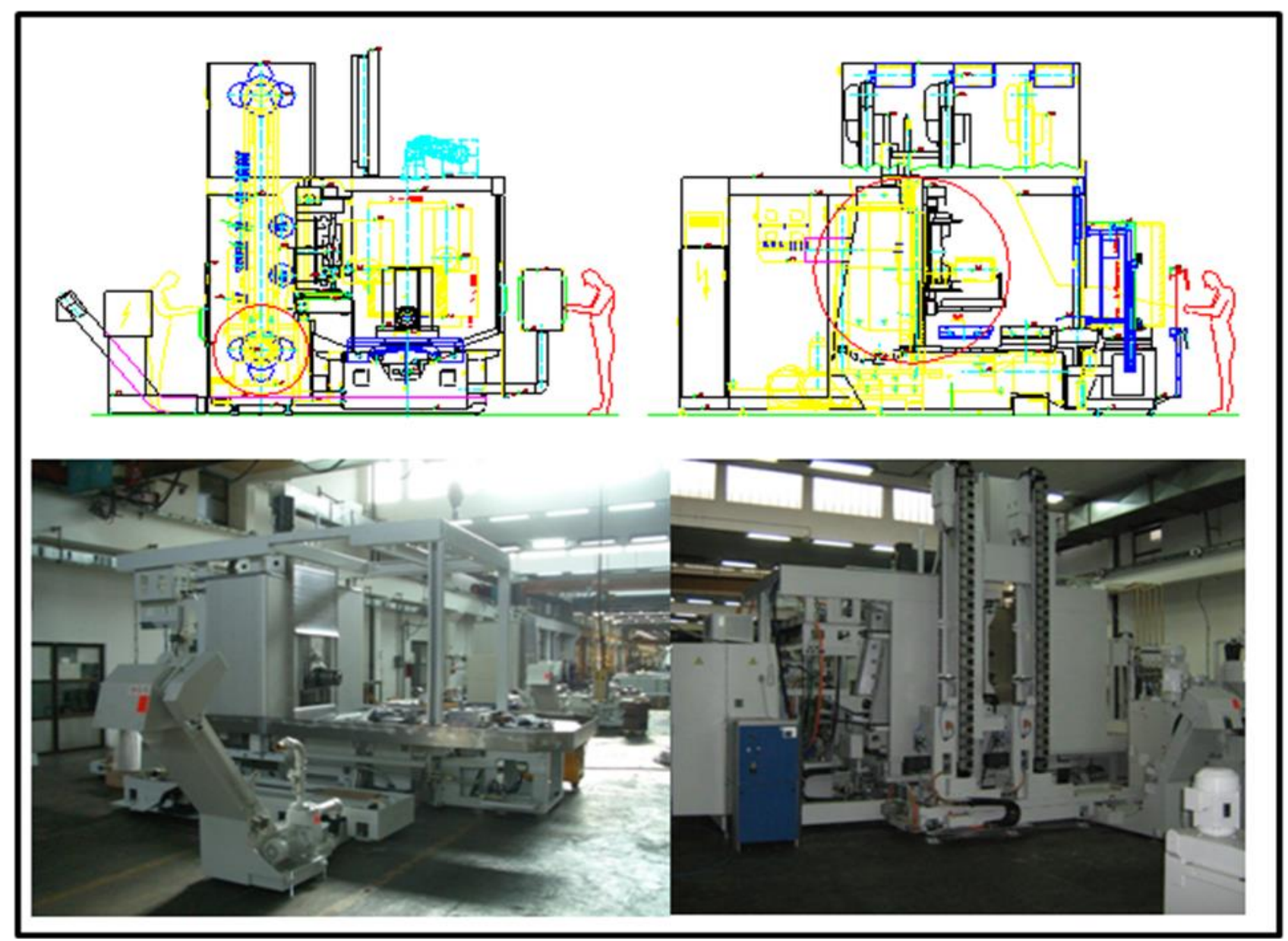

Fig. 7. TCF machining center (Brochures SAS, 2014)

\subsubsection{Flexible manufacturing systems}

The development of flexible technology leads to a considerable increase of productivity and cost effectiveness of production. To this end, the automated system, such as the production cell or machining stations, is needed so that the activities of machining and operating are maximally concentrated. Flexible automation, together with intelligent processes and machines, is the most modern trend of the technological development of production with discontinuous processes. The flexible machine tool is the basic component of flexible production. Due to the modular structure of hardware and software, it also enables development and connection into the computer integrated production (CIM). Requirements of production systems:

- rapid response to market demands,

- high flexibility,

- cost effectiveness,

- high equipment reliability,

- high product quality,

- high degree of utilization of the theoretically available working time,

- autonomous work,

- smallest possible number of cutting tools used,

- higher quality of produced and reliability of working without scrap,

- just in time technology,

- reduction of flow time and total time of production, 
Mulc, T.; Udiljak, T. \& Ciglar, D.: Structure of Reconfigurable Manufacturing Syst...

- increase of production in small series,

- development accordingly to the CIM concept.

The introduction of flexible machine tools and the increase of the degree of automation of production takes place gradually. This depends on the scope of production task, the required flexibility, automation, desire productivity and financial capacity of company. This requires an automated system, such as production cells or machine tools, thus ensuring maximum concentration of the machining and operating activities. Flexible automation ensures:

- concentration of several operations in one machining cell and machining with one clamping,

- machining of several technologically similar workpieces on the same production line or system, which is particularly important in small-lot production.

For larger lots and small quantities of workpieces, it can be justified to create compact and flexible systems, with one or more spindles operating simultaneously. With the right selection of the technological order, several operations at a single work station, the productivity of such systems is increased in comparison to the standard flexible manufacturing systems. Such a machine is adaptable given the assumed degree of change of the production process, which in turn reduces investment risk, Figure 8.
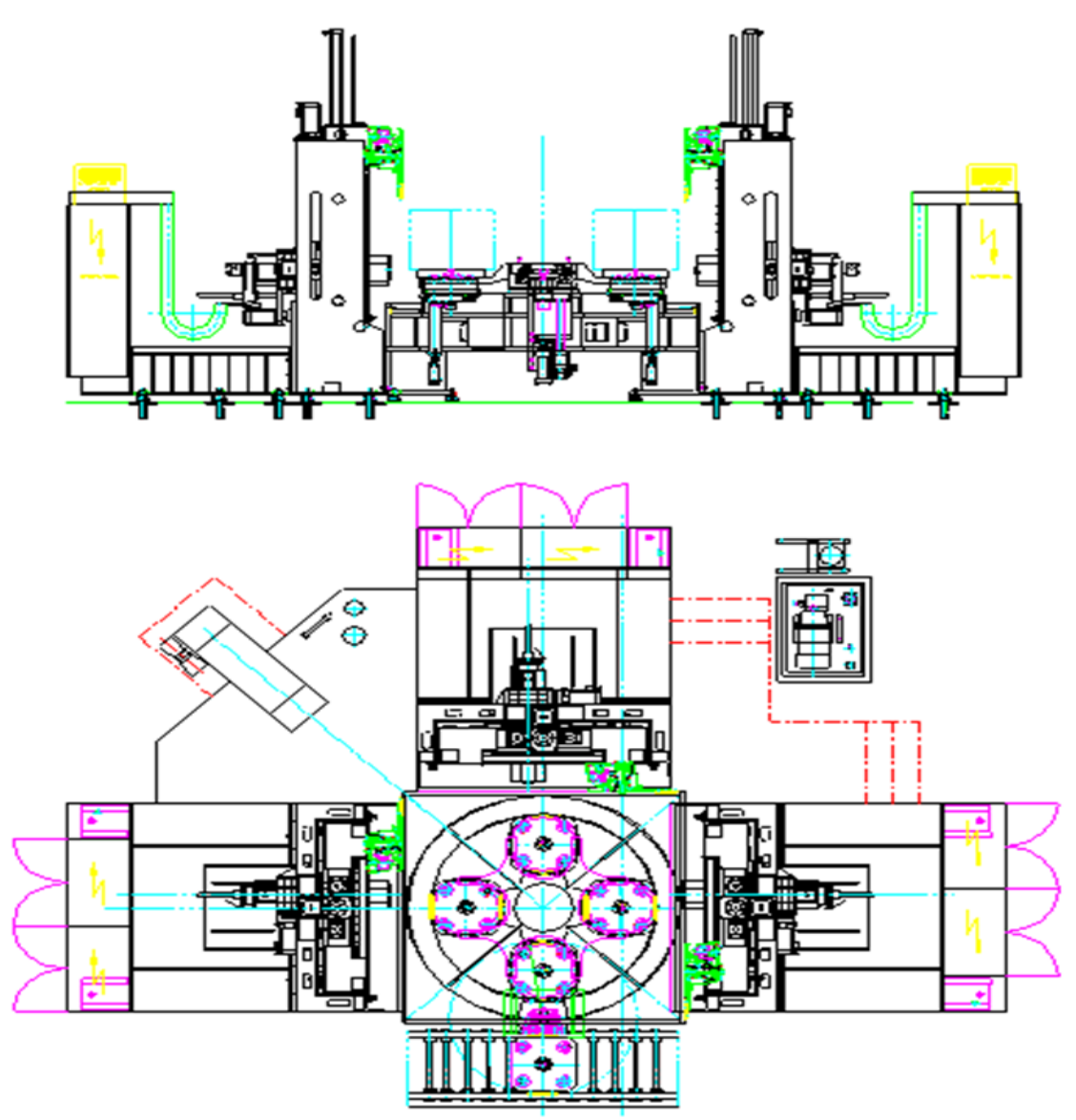

Fig. 8. Concept of connected machining centers in the circular flexible transfer (Brochures SAS, 2014) 


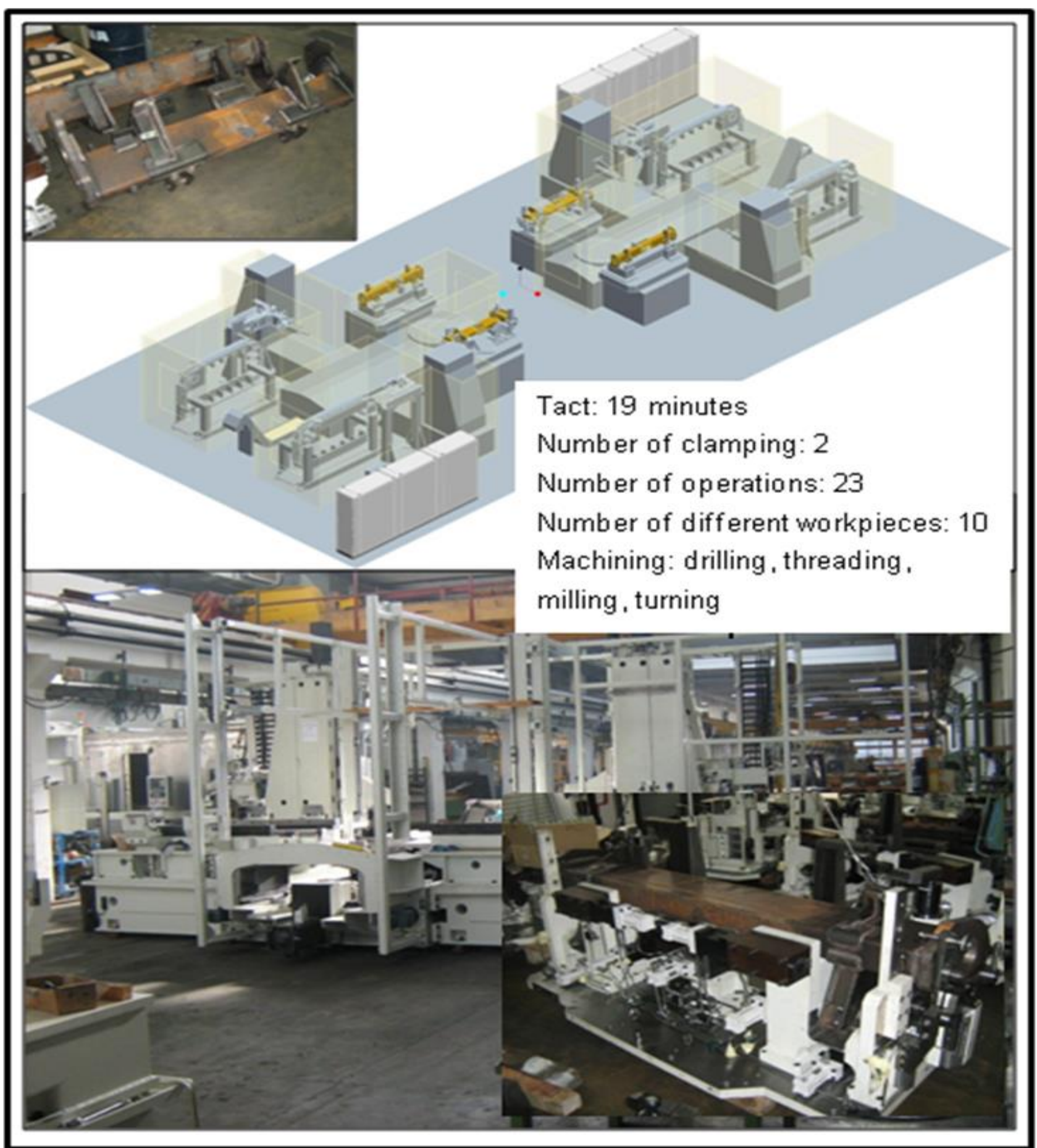

Fig. 9. Flexible manufacturing center with palette system (Brochures SAS, 2014)

\subsection{Reconfigurable production system}

Reconfigurable machines are a new class of machines that bridge the gap between highly flexible machines, and dedicated machines with low flexibility. The principle of designing flexible machines follows the philosophy of modular assembly of special machines, and is an approach to designing machines that are primarily used in high productivity manufacturing lines. Reconfiguration can be associated with changes in machine functionality or with its scalability, i.e. changes in production quantities or speed of executing operations. Reconfigurable production systems, as a definition, are designed for the production of product families, and aim to approach to cost efficiency 
Mulc, T.; Udiljak, T. \& Ciglar, D.: Structure of Reconfigurable Manufacturing Syst... of DMS with the adaptability of FMS. One of the first definitions of reconfigurable production systems was given by (Koren et al., 1999): "Reconfigurable manufacturing systems are designed for the rapid set-up of production capacity and functionality in relation to new conditions by reorganising or changing system components. "

The fundamental principles of designing RMS are:

- designing the machine with as much functionality as needed to process the family of workpieces, with the options that allow adaptation of functionality for receiving new workpieces from the same family of workpieces,

- designing the machine with the necessary capacity for the given family of workpieces, with the option that enables increasing machine capacity should the need arise.

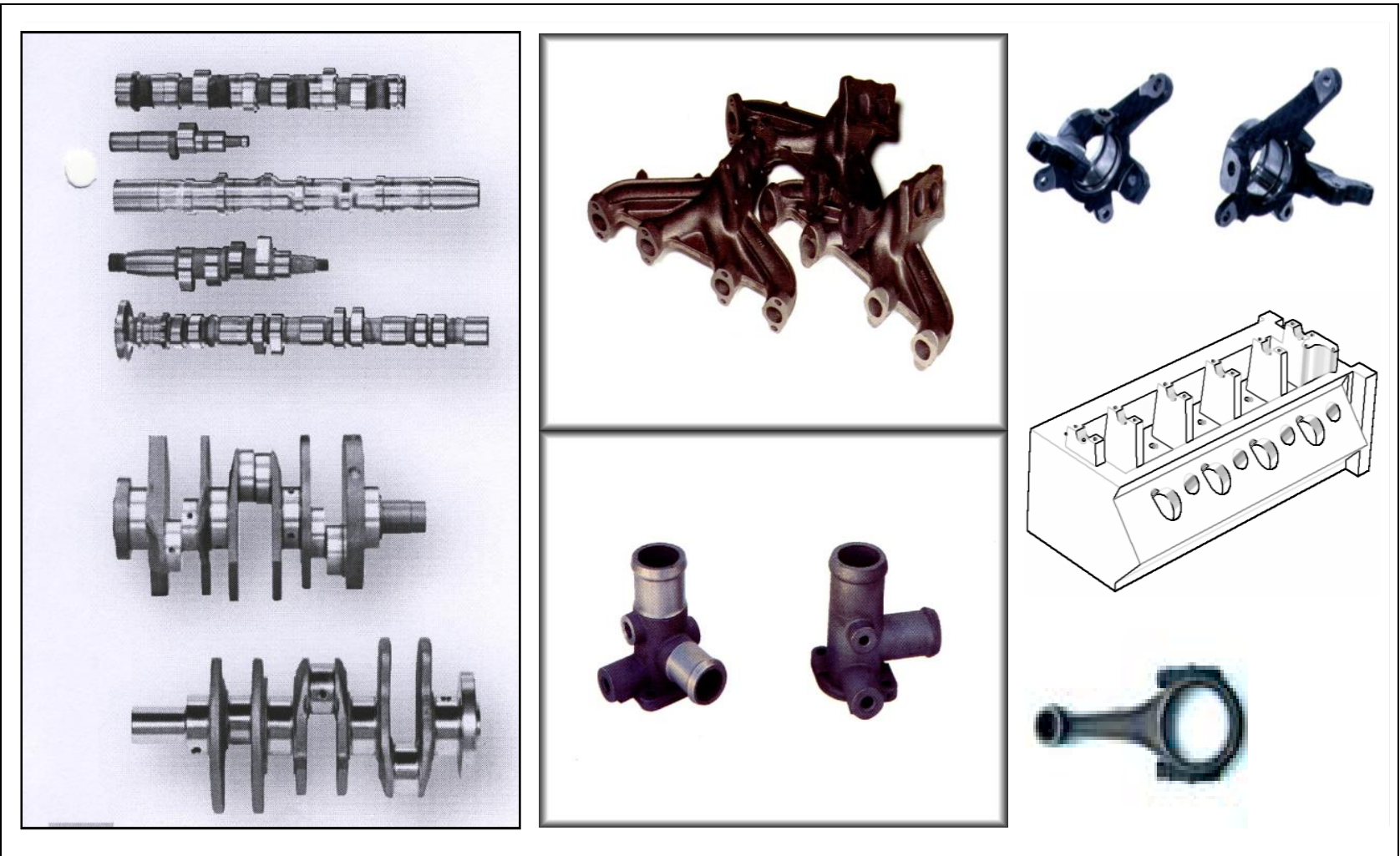

Fig. 10. Different categories of workpieces

The basic characteristics of RMSs are: modularity, scalability, and the abilities to integrate, convert, adjust and diagnose (Koren, 2010). The fundamental characteristic of RMSs is modularity (Bright et al., 2005). In a reconfigured system, the main components are the modules (system software, management, processing and processes). Since modularity is the main feature, the design principles are focused on decomposition, standardisation and exchangeability. According to (ElMaraghy, 2005), RMS designs are based on the principle of a constructive set of principles that enable adaptation to new requirements for the replacement, addition or removal of an individual module. 
The concept of the emergence and development of RMS remains tied to the family of possible workpieces, and the materials of which those workpieces are made, i.e. the technology group is the basis for the assembly of reconfigurable systems, Figure 10.

The main advantage of RMS systems is the adjustable flexibility of the "product family", with a lower investment cost than FMS. Each group of products has a specific technological property that differs significantly, such that the reconfigurable machines are shaped around a group of products with similar technological demands. While dedicated machines are designed for a specific workpiece for mass production, they are designed to perform individual operations with high reliability, repeatability and productivity, machines that use FMS are designed to execute a larger number of operations that can be changed depending on the workpiece, with a change to the computer program. The RMT concept lies between these two extremes; it contains the possibility of both hardware and software adjustments. The ideal reconfigurable system ensures precise functionality and the necessary production capacity, giving an economical solution at a given moment. The principles of designing reconfigurable production systems are:

- RMT offers adjustable production resources so as to respond to the unpredictable changes on the market and system appearances:

- capacity may be easily expandable in small steps,

- functionality may be very easily adjusted to new products,

- RMS allows for adjustments, which enable a rapid response to unexpected equipment failures;

- RMT is designed around a product or family of products, with sufficiently adaptable flexibility necessary to produce all the members of that family;

- the key characteristics of RMS is to install well conceived modular interface components (mechanical, communicational, control).

Dedicated and flexible manufacturing systems are static systems and RMS is a dynamic system that can change capacity and functionality depending on market trends. With a change in structure, the RMT can quickly change production capacity within the designed family. The different layouts and configurations of the production system are changed according to market needs, thus ensuring the necessary productivity, Figure 11.

Figure 11 clearly shows the individual areas of different concepts and their positioning with regard to functionality and capacity. Modularity, mechanical, electric and software interfaces are the foundation for reconfigurable systems. Achieving a short cycle of system reconfiguration requires an appropriately designed mechanical interface (Abele et al., 2007). The mechanical interface is achieved through various clamping elements, which secures high static and dynamic rigidity, high attenuation, low mass, compact form and simplicity of connecting and releasing, with high precision. In individual phases, it is possible to add or expand capacity, and with the same systems it is possible to change the product structure through changes, additions or removal of modules. 
Mulc, T.; Udiljak, T. \& Ciglar, D.: Structure of Reconfigurable Manufacturing Syst...

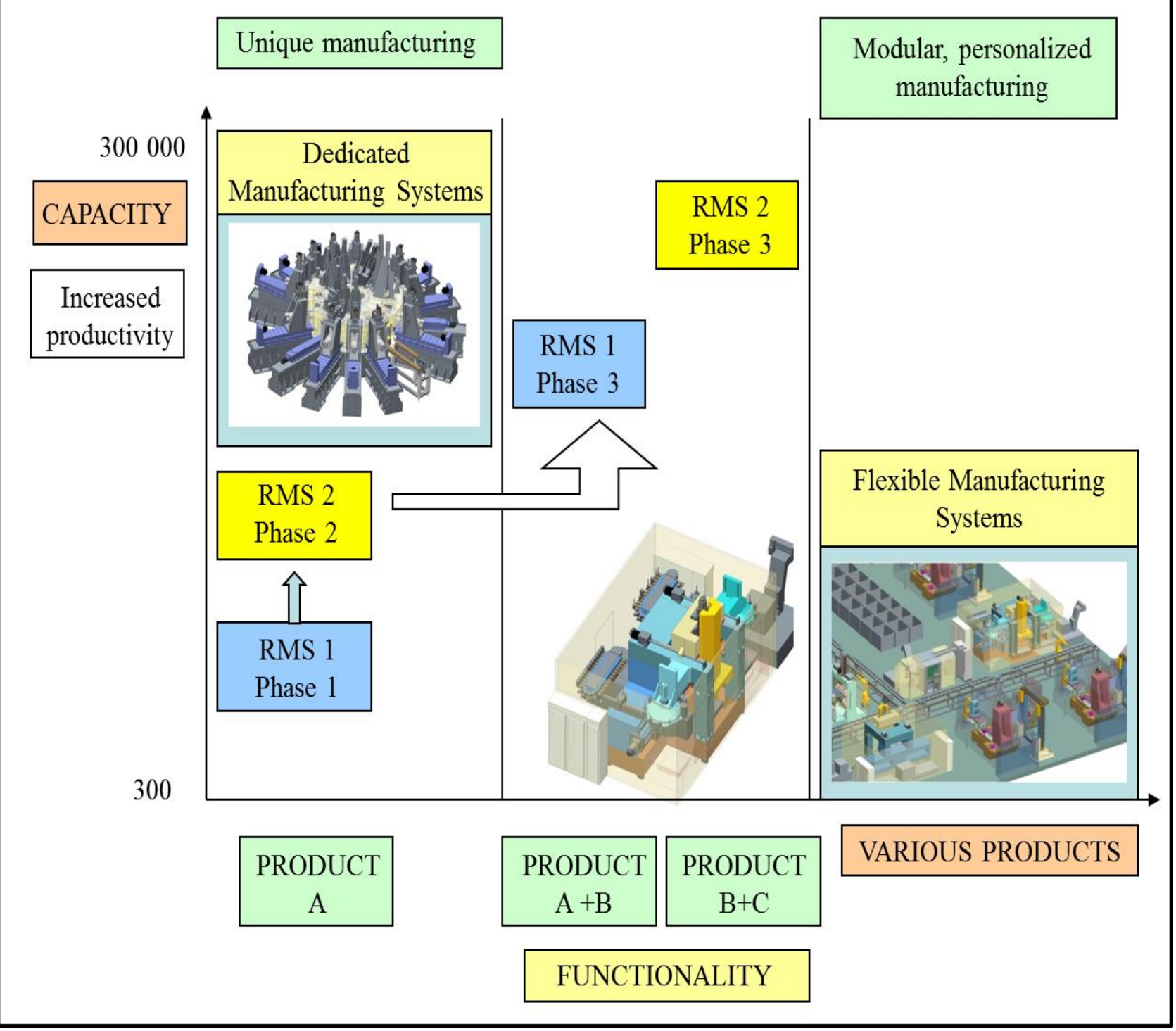

Fig. 11. Dedicated and flexible manufacturing systems

Designing of RMS should be performed in order to enable rapid changes to the hardware system configuration, production equipment and control structure. In the manufacturing process, unpredictable events can occur, which by their nature are dynamic variables with causes and effects that are difficult to foresee. In that sense, the modular structure of the RMS offers continual stable production, with the highest possible shortening of lag times and adjustments to new conditions, faster hardware, software and logistical changes, such as a rapid change of the production programme within the planned family of products.

\subsubsection{Reconfigurable process planning}

The reconfigurability of hardware components and systems is imperative for reconfigurable planning processes as part of the soft or logistic adaptability. The planning process must be adjustable and properly integrated in any efficient response that follows changes to production. The importance of information flow and communication, compatibility and an integral approach is particularly pronounced in this system. The different properties of process planning and methodology planning in 
reconfigurable manufacturing systems for planned and unplanned production changes must be specifically considered for each phase of reconfiguration.

The relations between product properties, the elements of process planning, and all modules of the manufacturing system and their capacities must be clearly ascertained. Modelling methods include the classification, determination of hierarchy rules, bringing together knowledge in the form of rules, limitation functions and more. The appropriate models need to be developed on the basis of: workpiece geometry (geometric models, production properties), technological limitations (hierarchy, base levels), limitations in production resources (capability, restrictions, capacity, size, availability) and knowledge of the processes (mathematical models, rules, heuristics, expert systems, intelligent systems).

\section{Conclusion}

A reduced lifespan, increased diversity and quality of products, with the simultaneous reduction in production costs have forced entire production chains to change and find alternative, effective production solutions. The limits of flexibility of manufacturing systems have been shifted through the development and management and drive systems, automation, monitoring and diagnostics, in addition to new processing technologies. High-speed, flexible manufacturing cells have been developed and have high efficiency, reliability and quality. By connecting these cells, it is possible to create a highly effective and flexible manufacturing system. Flexible manufacturing systems (FMS) ensure pre-planned generalised flexibility assembled $a$ priori, while dedicated machines are static systems built for a specific purpose. The best application of FMS is found in small lot manufacturing. In recent years, reconfigurable systems (RMS) have appeared as a response to market trends, as they can change capacity and functionality and thus rapidly respond to changes in the market. As such, reconfigurable systems represent an optimal solution between the demands for productivity and flexibility. The advantage of this approach for the adaptation to market needs is the faster capacity and higher production speed (larger series). The second important advantage of RMS is the faster ability to change the desired production volume and transformation, within reasonable costs. With the RMS concept, production capacities can vary from small to large series. Ultimately, in every specific case, it is necessary to find an optimal solution given the total production costs. In mass production of smaller workpieces, there will continue to be an inclination to develop flexible special machines, in which there is no recipe for simple solutions in selecting the concept and degree of flexibility. In most cases, adopting a reconfigurable modular system means that the set objectives are achieved by refiguring the hardware and software strategies. As such, the fundamental characteristics of future production systems would be:

- modularity as the basis for future development,

- development of mechanical, electrical and software interfaces,

- ability to apply intelligent sensory and diagnostic equipment to register and evaluate important events and current states of the system and its environment,

- ability to collect and to reapply important past experiences, 
Mulc, T.; Udiljak, T. \& Ciglar, D.: Structure of Reconfigurable Manufacturing Syst...

- ability to connect to external knowledge,

- ability to achieve an intelligent interface towards man and the environment.

From the above, it can be expected that the further progress of processing machinery will be towards the development of reconfigurable manufacturing systems of improved precision, efficiency and autonomy, within the framework of the accomplishments of contemporary technology. In such systems, a significant influence would be in the application of intelligent sensory devices and modern technology for signal processing. Assessing when to use a flexible cell, when to use a flexible special machine or transfer line, and when to use a reconfigurable machine will continue to be the task of the engineer. The overall task of planning processing processes must be in the hands of the manufacturer, as well as the user. In so doing, the fast, functional and coordinated work of various specialists is critical in preparing the concepts of supply and participation, even at the product production level.

\section{References}

Koren,Y. (2010). The Global Manufacturing Revolution: Product-Process-Business Integration and Reconfigurable Systems, John Wiley and sons, New Jersey.

ElMaraghy, H.A. (2005). Flexible and reconfigurable manufacturing systems paradigms, International Journal of Flexible Manufacturing Systems, Vol. 17. , No.4, pp.261-276.

Koren, Y.; Heisel, U.; Jovane, F.; Moriwaki, T.; Pritschow, G.; Ulsoy, G. \& Van Brussel, H. (1999). Reconfigurable Manufacturing Systems, Annals of the CIRP, Vol. 48, No.2, pp. 527540.

Mehrabi,M.G. ;Ulsoy,A.G. \& Koren,Y. (2000). Reconfigurable Manufacturing System: Key to Future Manufacturing, The University of Michigan, Ann Arbor, MI 48109-2123

Mehrabi, M.G.; Ulsoy, A.G.; Koren, Y. \& Heytler, P. (2002), Trends and perspectives in flexible and reconfigurable manufacturing systems, J Intell Manuf 13(2):135-146 Vukovic,A.; Ikonic,M.;Dobovicek,S. (2010). Reconfigurable Manufacturing System and the Need for New Taylorism, Eng.Rev. 30-2, pp. 71-82

Abele, E.; Worn, A. \& Kuhn, S. (2007), Design Princips for Reconfigurable Machine Tools, $11^{\text {th }}$ International Scientific Conference on Production Engineering CIM 2007, Abele,E; Udiljak,T. \& Ciglar,D.(Ed.), pp. 1-13, ISBN 978-953-97181-9-8, Biograd, $13^{\text {th }}-17^{\text {th }}$ June 2007, HUPS, Zagreb.

Bright, G.; Xing, B. \& Craig, S. (2005) Modular machine design for reconfigurable manufacturing. 3rd CIRP Conference on RMS, Ann Arbor, MI

Jüng,P. (1997). Bearbeitungszentren konkurieren mit Transferstraßen, Werkstatt und Betrieb, 130-7-8, S.540-546.

Brochures: SAS-Zadar. (2014). Croatia 